\title{
Human Study Subject
}

National Cancer Institute

\section{Source}

National Cancer Institute. Human Study Subject. NCI Thesaurus. Code C70665.

A living individual about whom an investig ator conducting research obtains data through intervention or interaction with the individual or through identifiable private information. 